Revista Brasileira de Meteorologia, v.28, n.1, 75 - 84, 2013

\title{
ANÁLISE E ESTIMATIVA DOS COMPONENTES DO BALANÇO DE ENERGIA EM ECOSSISTEMA DE MANGUEZAL AMAZÔNICO.
}

\author{
PRISCILA LIMA PEREIRA E HERNANI JOSÉ BRAZÃO RODRIGUES
}

\author{
Universidade Federal do Pará (UFPA), Belém, PA, Brasil \\ pl.pereira@yahoo.com.br, hernani@ufpa.br
}

Recebido Abril de 2010 - Aceito Setembro de 2012

\begin{abstract}
RESUMO
As medições e estimativas dos componentes do balanço de energia foram feitos acima da copa das árvores no ecossistema de manguezal natural, localizada a $30 \mathrm{~km}$ da cidade de Bragança-PA, entre novembro de 2002 e agosto de 2003. Os dados foram utilizados para a análise das variações sazonais e horárias do fluxo de calor sensível e calor latente, bem como a avaliação da partição de energia. Os dados meteorológicos foram coletados pela estação meteorológica automática (EMA) e os fluxos foram calculados utilizando-se a técnica de covariância de vórtices turbulentos. Os modelos de Penman-Monteith e Shuttleworth foram usados para estimar o fluxo de calor sensível e calor latente. O objetivo deste estudo foi analisar o equilíbrio e a partição de energia no manguezal, assim como fazer uma avaliação do comportamento de modelos empíricos para estimar os fluxos de energia. $\mathrm{O}$ saldo de radiação apresentou valores mais elevados no período menos chuvoso. A razão de Bowen mostrou valor geralmente baixo, o que indica que uma proporção maior de energia foi utilizada sob a forma de calor latente. O modelo Shuttleworth é mais eficiente na estimativa de fluxos de calor sensível. Para estimar o fluxo de calor latente do modelo de Penman-Monteith foi mais eficiente durante a estação seca e o modelo Shuttleworth durante a estação chuvosa.
\end{abstract}

Palavras-chave: Ecossistema Amazônico, Manguezal, Balanço de energia.

\begin{abstract}
ANALYSIS AND ESTIMATION OF ENERGY BALANCE COMPONENTS IN AMAZONIAN MANGROVE ECOSYSTEM

Measurements and estimates of the components of energy balance were made above the canopy of trees in natural mangrove ecosystem, located $30 \mathrm{~km}$ from the city of Bragança-PA, between November 2002 and August 2003. The data were used in the analysis of seasonal and hourly variations of the sensible and latent heat flows, as well as the evaluation of the energy partition. Meteorological data were collected by the automatic weather station (AWS) and the energy flows were calculated using the technique of eddy covariance. The Penman-Monteith and Shuttleworth models were used to estimate the sensible and latent heat flow. The objective of this study was to analyze the balance and partitioning of energy in the mangrove and make an assessment of the behavior of empirical models in estimating the energy flows. The net radiation showed higher values in the less rainy season. The Bowen ratio showed generally low value, which indicates that a greater proportion of energy was used in the form of latent heat. The estimates of the energy flows showed satisfactory results. Shuttleworth model is more efficient in estimating sensitive heat flows. For estimating latent heat flow the PenmanMonteith model was more efficient during dry season and the Shuttleworth model during rainy season. Keywords: Ecossystem amazônico, Mangrove, Energy balance.
\end{abstract}




\section{INTRODUÇÃO}

A coleta de dados para análise e estimativa dos componentes do balanço de energia, em especial os fluxos de calor sensível e calor latente em um ecossistema de manguezal amazônico, são de fundamental importância para se conhecer o comportamento dos componentes do balanço de energia neste tipo de ecossistema.

Este estudo foi realizado na cidade de Bragança-PA (lat.: $-01^{\circ} 03^{\prime} 13^{\prime \prime}$ e long.: $\left.-46^{\circ} 45^{\prime} 56^{\prime \prime}\right)$, onde o clima da região é caracterizado como quente e muito úmido, com duas estações distintas: chuvosa (janeiro a junho) e menos chuvosa (julho a dezembro). Essa sazonalidade reflete o efeito do deslocamento da Zona de Convergência Intertropical (ZCIT) sobre a região (INMET, 1992).

Diversos métodos são utilizados para este tipo de medição, atualmente o mais utilizado é o que aplica a técnica de correlação de vórtices turbulentos (eddy covariance). Calcula-se a covariância entre as flutuações na componente vertical da velocidade do vento, simultaneamente com a quantidade conservativa de interesse na amostra de ar coletado, através do analisador de gás infravermelho. Este método vem sendo reconhecido como a forma mais confiável e direta para monitorar o comportamento desses fluxos a curto, médio ou longo prazo em diferentes ecossistemas MALHI et al. (1998). Contudo, a utilização desse sistema é relativamente caro e demanda constante presença na área de coleta de dados e manutenção para obtenção de uma série contínua e confiável. Dessa forma, é importante que se busque outras formas para obtenção de medidas desses fluxos, e uma delas seria a utilização de modelos mecanísticos que possam estimar estes fluxos com base em algumas medições mais simples efetuadas no manguezal. Neste estudo os métodos escolhidos para serem utilizados para determinação dos fluxos, em uma tentativa de se mostrar que meios mais econômicos e práticos como os modelos mecanísticos Shuttleworth e Penman-Monteith, podem ser utilizados como alternativas em casos extremos de ausência ou falha dos instrumentos.

A análise das variações médias horárias e mensais dos componentes do balanço de energia e dos fluxos de calor latente e calor sensível, podem colaborar para se ter um melhor conhecimento a respeito deste ecossistema.

Este estudo é uma proposta de contribuição às pesquisas que vem sendo desenvolvidas em ecossistema de manguezal na Amazônia e tem como objetivos: avaliar as variações horárias e mensais dos componentes do balanço de energia, quantificar a partição de energia neste ecossistema utilizando razão de Bowen e, finalmente, avaliar a eficiência dos métodos propostos por Shuttleworth e Penman-Monteith na estimativa dos fluxos de energia no manguezal.

\section{MATERIAIS E MÉTODOS}

\subsection{Localização e descrição do sitio experimental}

Localizado no município de Bragança, nordeste do Estado do Pará, o manguezal natural em estudo fica a $150 \mathrm{~km}$ de distância da foz sul do rio Amazonas e estende-se por uma faixa de aproximadamente $20 \mathrm{~km}$ de largura, com uma área total estimada em $120 \mathrm{~km}^{2}$. O clima da região é caracterizado como quente e muito úmido, com duas estações distintas: chuvosa (janeiro a junho) e menos chuvosa (julho a dezembro). Essa sazonalidade reflete o efeito do deslocamento da Zona de Convergência Intertropical (ZCIT) sobre a região (INMET, 1992).

\subsection{Medições e sistema de aquisição de dados}

Os dados utilizados foram coletados, no período de novembro de 2002 a agosto de 2003, para medição das variáveis meteorológicas necessárias à caracterização do microclima do manguezal e também para utilização como dados de entrada nos modelos empíricos, tendo como base de instalação a torre micrometeorológica, onde foram abrigados os seguintes instrumentos: (EMA) estação meteorológica automática (Tabela 1)

E através do EDISOL que é composto por um anemômetro sônico tridimensional que mede as três componentes do vento, um analisador de gás a infravermelho, um gabinete com microcomputador e um software EDIRE para aquisição de dados de alta frequência, como determinação dos fluxos de calor sensível e calor latente em tempo real Moncrieff et al. (1997). O mesmo sistema foi utilizado com eficiência na determinação do balanço de energia em uma cultura de feijão caupi no estado do Pará Neves et al. (2008).

O sistema EDISOL utiliza a técnica de correlação de vórtices turbulentos ("eddy covariance") e calcula a covariância entre as flutuações na componente vertical da velocidade do vento, simultaneamente com a quantidade conservativa de interesse na amostra de ar coletado, ou seja, para se ter o fluxo de calor sensível é necessário a covariância da velocidade vertical do vento e da temperatura, já para o fluxo de calor latente se tem a covariância entre a velocidade vertical do vento e umidade específica. Obtêm-se as equações:

$$
\begin{aligned}
& H=\rho C_{p} \overline{w^{\prime} T^{\prime}} \\
& L E=L_{v} \overline{w^{\prime} q^{\prime}}
\end{aligned}
$$

Em que: $\rho=$ densidade absoluta do ar; $C_{p}=$ calor específico do ar à pressão constante; $w=$ flutuação da componente vertical da velocidade do vento; $T^{\prime}=$ desvio instantâneo a partir da média da 
Tabela 1 - Relação das variáveis meteorológicas coletadas na Estação Meteorológica Automática (EMA) com unidade de medida, identificação dos sensores e altura/profundidade de instalação.

\begin{tabular}{l|l|l|l}
\hline MEDIDAS & UNIDADES & INSTRUMENTO/MODELO & ALTURA \\
\hline Temperatura do ar & $\left({ }^{\circ} \mathrm{C}\right)$ & Temperature Probe HMP45C & $27 \mathrm{~m}$ \\
\hline Direção do vento & $\left({ }^{\circ}\right)$ & Wind Sentry model 03001 & $27 \mathrm{~m}$ \\
\hline Velocidade do vento & $\left(\mathrm{m} \cdot \mathrm{s}^{-1}\right)$ & Wind Sentry model 03001 & $27 \mathrm{~m}$ \\
\hline Umidade relativa & $(\%)$ & Relative Humidity Probe HMP45C & $27 \mathrm{~m}$ \\
\hline Radiação solar global & $\left(\mathrm{W} . \mathrm{m}^{-2}\right)$ & $\begin{array}{l}\text { Pyranometer } \\
\text { LITE(Kipp\&Zonen) }\end{array}$ & $27 \mathrm{~m}$ \\
\hline Saldo de radiação & $\left(\mathrm{W} . \mathrm{m}^{-2}\right)$ & Net Radiometer Q-7. 1 & $27 \mathrm{~m}$ \\
\hline Precipitação & $(\mathrm{mm})$ & CSI model CS700-L & $27 \mathrm{~m}$ \\
\hline Radiação PAR & $\left(\mu \mathrm{mol} . \mathrm{m}^{-2} . \mathrm{s}^{1}\right)$ & Quantum Sensor LI-190SB & $1 \mathrm{~m}, 16 \mathrm{~m}, 27 \mathrm{~m}$ \\
\hline Temperatura do solo & $\left({ }^{\circ} \mathrm{C}\right)$ & Temperature Probe model 108 & $-5 \mathrm{~cm},-20 \mathrm{~cm},-50 \mathrm{~cm}$ \\
\hline
\end{tabular}

temperatura do ar; $q^{\prime}=$ desvio instantâneo a partir da média da umidade específica; $L_{v}=$ calor latente de vaporização da água.

\subsection{Modelos empíricos aplicados para balanço de energia}

\subsubsection{Fluxos de calor sensível (H) e calor latente (LE) pelo método de Shuttleworth}

Utilizou-se este método de Shuttleworth (Shuttleworth, 1988 para calcular o fluxo de calor sensível entre o dossel do mangue e a atmosfera, que determina o transporte de calor sensível entre o dossel global a um nível de referência, com o método das resistências:

$$
H=\rho C_{p}\left(\frac{T_{f}-T_{a}}{r_{a}}\right)
$$

Em que: $\rho=$ é a massa específica do ar seco a uma atmosfera (1 atm.) $\left(1,2 \mathrm{~kg} \cdot \mathrm{m}^{-3}\right) ; C_{p}=$ calor específico do ar a pressão constante a $20{ }^{\circ} \mathrm{C}\left(\mathrm{J} \cdot \mathrm{kg}^{-1} \cdot \mathrm{K}^{-1}\right) ; r_{a}=$ resistência aerodinâmica $\left(\mathrm{s} . \mathrm{m}^{-1}\right) ; T_{f}=$ temperatura da superfície foliar $\left({ }^{\circ} \mathrm{C}\right) ; T_{a}=$ temperatura do ar próximo à superfície $\left({ }^{\circ} \mathrm{C}\right)$, período chuvoso: $T_{f}=-43,345+2,6019$. Tar, período menos chuvoso: $T_{f}=-38,465+2,4241$. Tar.

Para determinar a resistência aerodinâmica $\left(\mathrm{r}_{\mathrm{a}}\right)$, utiliza-se a Equação parametrizada por (Nichols, 1992; Santos Alvalá, 1993):

$$
r_{a}=\frac{r_{b}}{2 I A F}
$$

Em que: $I A F=$ índice de área foliar do manguezal; $r_{b}=$ resistência média da camada limite por unidade de área de vegetação em s.m $\mathrm{m}^{-1}$.

Para o cálculo do fluxo de calor latente o mesmo método apresenta uma relação similar àquela proposta para o calor sensível, sendo que o transporte de vapor d'água entre a vegetação e a atmosfera, será influenciado pela resistência aerodinâmica $\left(r_{a}\right)$ e a resistência estomática $\left(r_{s}\right)$. Através da Equação 5 pode-se determinar o fluxo de calor latente.

$$
L E=\rho\left(\frac{C_{p}}{\gamma}\right)\left(\frac{e_{s\left(T_{f}\right.}-e}{r_{a}+r_{s}}\right)
$$

Em que: $\mathrm{e}_{\mathrm{s}}\left(T_{f}\right)=$ pressão de saturação do vapor à temperatura da folha (hPa); $e=$ pressão de vapor à temperatura do ar na altura considerada (hPa); $\gamma=$ constante psicrométrica $\left(\mathrm{hPa} . \mathrm{K}^{-1}\right) ; r_{a}=$ resistência aerodinâmica $\left(\mathrm{s} \cdot \mathrm{m}^{-1}\right) ; r_{s}=$ resistência estomática $\left(\mathrm{s} . \mathrm{m}^{-1}\right) ; C_{p}=$ calor específico do ar a pressão constante a $20^{\circ} \mathrm{C}\left(\mathrm{J} \cdot \mathrm{kg}^{-1} \cdot \mathrm{K}^{-1}\right) ; \rho=$ densidade.

A resistência estomática $\left(r_{s}\right)$ é o mecanismo de controle fisiológico da transpiração vegetal, cujas variações resultam também a partir das mudanças no comportamento da radiação solar, umidade do solo, disponibilidade de água nas folhas, temperatura do ar, concentração de $\mathrm{CO}_{2}$ e déficit de umidade específica, sendo determinada da seguinte forma (Dickinson, 1984).

$$
r_{s}=r_{s \min } \times F_{r g}
$$

Em que: $r_{\text {smin }}=$ resistência estomática mínima $\left(\mathrm{s} . \mathrm{m}^{-1}\right) ; F_{r g}=$ função que representa a influência da radiação solar global $\left(\mathrm{R}_{\mathrm{g}}\right)$ na resistência estomática.

\subsubsection{Fluxos de calor sensível (H) e calor latente (LE) pelo método de Penman-Monteith}

As trocas de calor sensível entre o dossel do mangue e a atmosfera, serão determinadas pelas condições de estabilidade da camada limite atmosférica e pelas propriedades da superfície. Analogamente à determinação do fluxo de calor sensível pela metodologia de Shuttleworth, será também utilizado, neste processo, o método das resistências (Penman-Monteith, 1965).

$$
H=\rho C_{p}\left(\frac{T_{f}-T_{a}}{r_{a}}\right)
$$




$$
r_{a}=\frac{\ln \left[\left(Z_{m}-d\right) / Z_{o m}\right] \ln \left[\left(Z_{e}-d\right) / Z_{o e}\right]}{K^{2} U_{z}}
$$

Calcula-se a resistência aerodinâmica $\left(\mathrm{r}_{\mathrm{a}}\right)$ através da Equação 8 (Brutsaert, 1982), em que: $Z_{m}=$ altura da medida da velocidade do vento $(\mathrm{m}) ; Z_{e}=$ altura da medida da umidade do $\operatorname{ar}(\mathrm{m}) ; Z_{\text {om }}=$ comprimento da rugosidade para o transporte de momentum, (m); $Z_{o e}=$ comprimento de rugosidade para o transporte de vapor e calor sensível $(\mathrm{m}) ; d=$ deslocamento do plano zero $(\mathrm{m}), d=0,65 \mathrm{~h} ; U_{z}=$ velocidade do vento na altura $\mathrm{z}\left(\mathrm{m} . \mathrm{s}^{-1}\right) ; K=$ constante de Von Karmann $(0,41) ; \ln =$ logaritmo natural (John Napier); $h=$ altura do dossel.

O fluxo de calor latente para manguezais ocorre quando há uma diferença na concentração de vapor d'água entre a atmosfera e a vegetação. O transporte de vapor d'água do dossel para a atmosfera ocorre pelos processos de evaporação e transpiração (evapotranspiração), no caso da transpiração o vapor d'água deve difundir-se através da abertura estomatal para em seguida ser difundido no ar. Para a determinação do calor latente utiliza-se o modelo de (Penman - Monteith, 1965), o qual abrange os componentes aerodinâmicos e do balanço de energia.

$$
L E=\frac{\Delta\left(R_{n}-G\right)+\rho_{a} C_{p}\left(e_{s}-e_{a}\right) / r_{a}}{\Delta+\gamma\left(1+r_{s} / r_{a}\right)}
$$

Em que: $\Delta=$ declividade da curva de pressão de saturação do ar a temperatura (t); $R_{n}=$ saldo de radiação (W.m $\left.{ }^{-2}\right) ; G=$ fluxo de calor no solo (W.m $\left.{ }^{-2}\right) ; \rho_{a}=$ densidade média do ar $(1,2$ $\left.\mathrm{kg} \cdot \mathrm{m}^{-3}\right) ; C_{p}=$ calor específico do ar à pressão constante $\left(\mathrm{J} \cdot \mathrm{kg}^{-1}\right.$. $\left.\mathrm{K}^{-1}\right) ; \gamma=$ constante psicrométrica $\left(\mathrm{hPa} . \mathrm{K}^{-1}\right) ; r_{s}=$ resistência estomática $\left(\mathrm{s} . \mathrm{m}^{-1}\right) ; r_{a}=$ resistência aerodinâmica $\left(\mathrm{s} . \mathrm{m}^{-1}\right) ; e_{s}=$ pressão de saturação do vapor d'água; $e_{a}=$ pressão de vapor à temperatura do ar; $\Delta=4098 . \mathrm{e}_{\mathrm{s}} /\left(\mathrm{T}_{\mathrm{ar}}+273,3\right)^{2}$

Para se determinar a resistência estomática $\left(\mathrm{r}_{\mathrm{s}}\right)$ utiliza-se o modelo definido por (Mielke, 1999), pois este processo leva em consideração a região tropical para períodos secos e úmidos ao longo do ano.

$$
r_{s}=\frac{120,26 \times r_{e}^{\prime} \times P}{273,15+T_{a r}}
$$

Em que: $r_{e}{ }^{\prime}=$ termo para determinação da resistência estomática $\left(\mathrm{mol} \cdot \mathrm{m}^{-1} \cdot \mathrm{s}^{-1}\right), P=$ pressão atmosférica $(\mathrm{kPa}), T_{a r}=$ temperatura média do ar $\left({ }^{\circ} \mathrm{C}\right)$.

\subsubsection{Equação da partição de energia $(\beta)$}

A variação temporal e sazonal da partição dos componentes do balanço de energia foi determinada pela fração do saldo de radiação, que será utilizado pelo calor sensível (H/ $\mathrm{Rn})$ e calor latente ( $L E / \mathrm{Rn})$, e a partição de energia disponível na superfície é determinada através da Razão de Bowen $(H / L E)$.

$$
\beta=\frac{H}{L E}
$$

Em que: $H=$ fluxo de calor sensível do ar $\left(\mathrm{W} \cdot \mathrm{m}^{-2}\right) ; L E=$ fluxo de calor latente de evaporação da água (W.m ${ }^{-2}$ ).

O valor da Razão de Bowen é adimensional dependendo essencialmente das condições hídricas da superfície evaporante. Para uma superfície úmida, o valor resultante deverá ser baixo, uma vez que a maior parte do saldo de radiação $(\mathrm{Rn})$ será utilizada para evaporar a água superficial (calor latente). Se a superfície estiver seca, o valor resultante deverá ser alto, uma vez que neste caso, a maior parte do saldo de radiação será utilizado para o aquecimento do ar (calor sensível). Pereira et al. (1997).

\section{RESULTADOS}

\subsection{Determinação das estações características da região}

A Figura 1 corresponde à precipitação medida na estação durante o período de estudo, juntamente com a série climatológica da cidade de Tracuateua de 1976 a 1998, região vizinha a Bragança. Portanto, pode-se perceber que a climatologia de precipitação mostrada é a esperada para região, com maiores tendências de precipitação no intervalo que se estende de janeiro a junho com um decréscimo de julho até dezembro.

\subsection{Variação temporal dos componentes do balanço de energia}

As variações médias dos componentes do balanço de energia correspondente ao período de novembro de 2002 a agosto de 2003 e estão ilustradas nas Figuras 2 a 11.

Os valores medidos do saldo de radiação foram aqui relacionados diretamente com os fluxos de calor sensível e calor latente. É importante destacar que durante o período de coleta houve ausência de dados em alguns momentos, cujos meses mais deficientes foram novembro (Figura 2) e abril (Figura 7) ambos com nove dias de coleta.

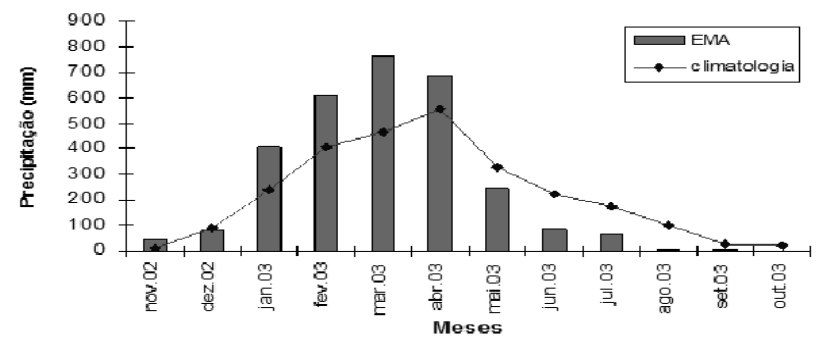

Figura 1 - Distribuição da precipitação medida no sítio experimental e série climatológica (76 a 98) da estação de Tracuateua (INMET). 
Na estação chuvosa (janeiro a junho) os valores extremos de máximo e mínimo do saldo de radiação foram encontrados no mês de junho (Figura 9), com 640,3 W/m² (12:30 horas) e -35,73 $\mathrm{W} / \mathrm{m}^{2}$ (05:00 horas) respectivamente, com média de $123,57 \mathrm{~W} /$ $\mathrm{m}^{2}$. Já para a estação menos chuvosa (julho a dezembro) foram encontrados os valores mais elevados de saldo radiação, que variaram no geral entre 600 a $700 \mathrm{~W} / \mathrm{m}^{2}$ tendo em vista que a ZCIT não atua nesta época, o que facilita a passagem de mais radiação devido à diminuição de nebulosidade, os extremos de máximo e mínimo foram registrados ambos no mês de novembro (Figura 2) com $631,67 \mathrm{~W} / \mathrm{m}^{2}$ (13:00 horas) e -42,96 $\mathrm{W} / \mathrm{m}^{2}$ (19:30 horas) respectivamente, com média de 155,63 W/ $\mathrm{m}^{2}$ para o período.

Na estação menos chuvosa o fluxo de calor latente obteve seu máximo no mês de maio (Figura 8), com o valor de 374,75 $\mathrm{W} / \mathrm{m}^{2}$ às 11:00 horas e seu mínimo foi no mês de abril (Figura 7), com $-35,32 \mathrm{~W} / \mathrm{m}^{2}$ às 20:00 horas. Como já se esperava, os menores valores foram encontrados no período da noite uma vez

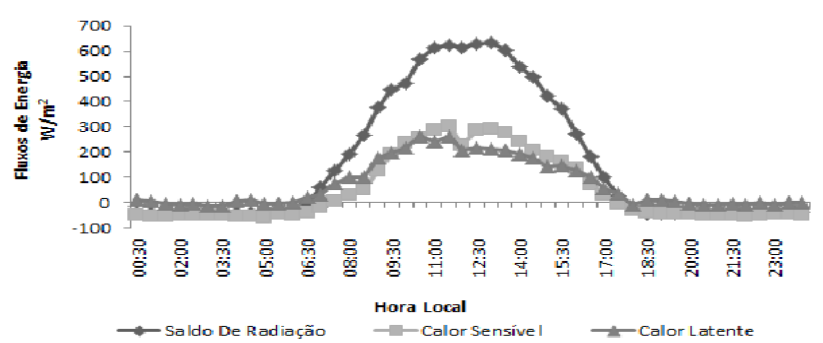

Figura 2 - Variação média horária do saldo de radiação, fluxo de calor sensível (H) e fluxo de calor latente (LE) em novembro de 2002.

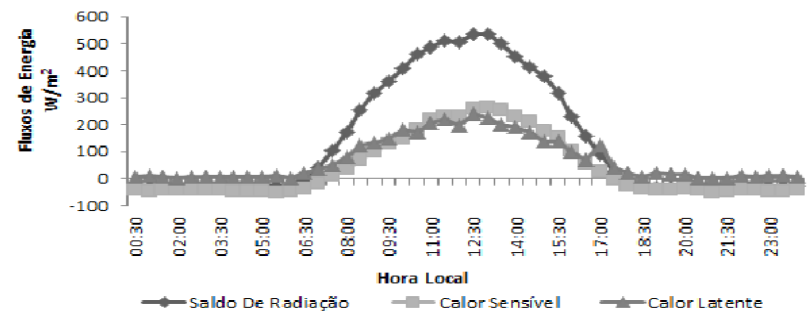

Figura 3 - Variação média horária do saldo de radiação, fluxo de calor sensível (H) e fluxo de calor latente (LE) em dezembro de 2002.

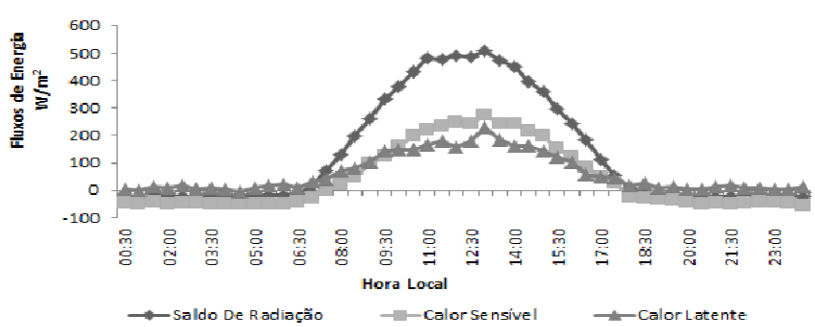

Figura 4 - Variação média horária do saldo de radiação, fluxo de calor sensível (H) e fluxo de calor latente (LE) em Janeiro de 2003.

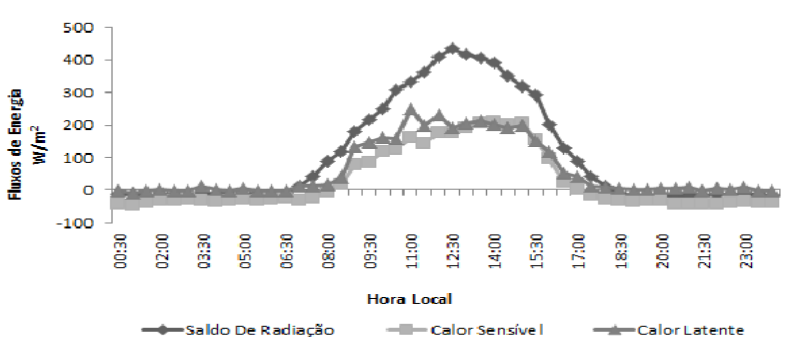

Figura 5 - Variação média horária do saldo de radiação, fluxo de calor sensível (H) e fluxo de calor latente (LE) em Fevereiro de 2003.

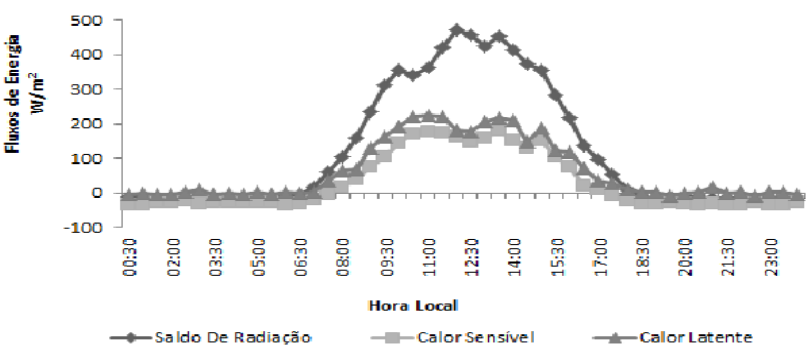

Figura 6 - Variação média horária do saldo de radiação, fluxo de calor sensível (H) e fluxo de calor latente (LE) em Março de 2003.

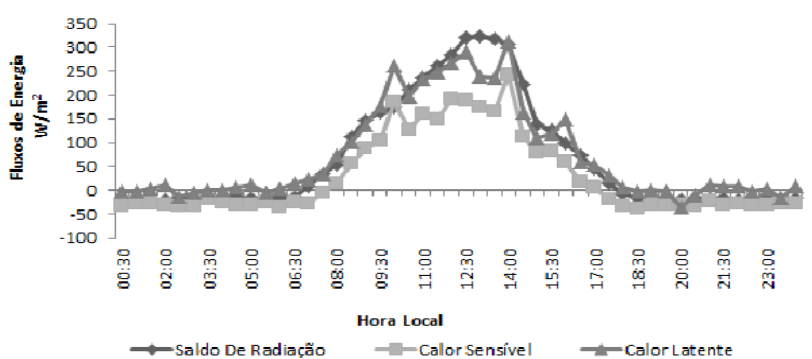

Figura 7 - Variação média horária do saldo de radiação, fluxo de calor sensível (H) e fluxo de calor latente (LE) em Abril de 2003.

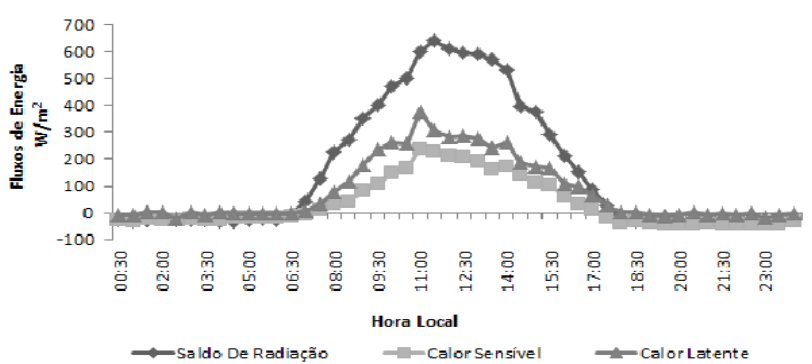

Figura 8 - Variação média horária do saldo de radiação, fluxo de calor sensível (H) e fluxo de calor latente (LE) em Maio de 2003.

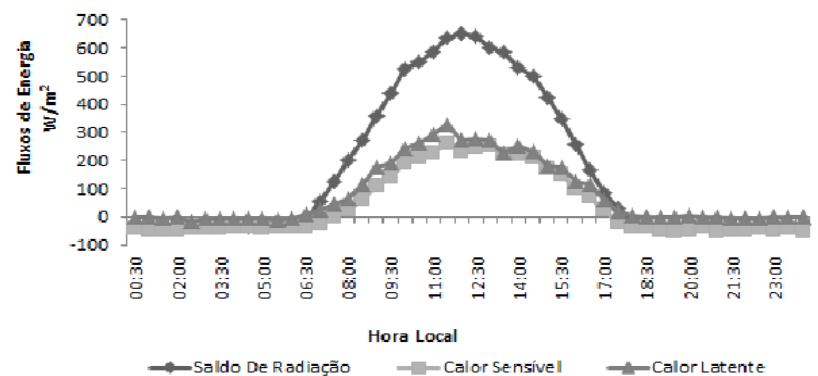

Figura 9 - Variação média horária do saldo de radiação, fluxo de calor sensível (H) e fluxo de calor latente (LE) em Junho de 2003. 
que a evaporação ocorre de forma bem ponderada neste horário. No fluxo de calor sensível, os extremos de máximo e mínimo foram encontrados no mês de janeiro (Figura 4), com 274,74 W/ $\mathrm{m}^{2}$ às $13: 00$ horas $\mathrm{e}-52,78 \mathrm{~W} / \mathrm{m}^{2}$ às $00: 00$ horas respectivamente.

$\mathrm{Na}$ estação chuvosa o calor sensível registrou no mês de novembro (Figura 2) o máximo de $300,18 \mathrm{~W} / \mathrm{m}^{2}$ às 11:30 horas e mínimo de $-59,33 \mathrm{~W} / \mathrm{m}^{2}$ às 05:00 horas e para o fluxo de calor latente se tem os extremos de máximo de $267,47 \mathrm{~W} /$ $\mathrm{m}^{2}$ às 12:00 horas e o mínimo de $-15,97 \mathrm{~W} / \mathrm{m}^{2}$ às $03: 30$ horas, ambos em junho (Figura 9).

Os dois fluxos fazem traçados semelhantes ao do saldo de radiação, ao longo do dia, com calor sensível apresentando valores maiores do que o calor latente durante a época menos chuvosa, entre o período da manhã e fim de tarde, devido ao fato de haver uma maior quantidade de energia disponível. Em janeiro (Figura 4) ainda se percebe esta configuração, que começa a se inverter em fevereiro (Figura 05) e se estende ate junho (Figura 9).

A variação sazonal dos componentes do balanço de energia pode ser vista na (Figura 12). Observa-se nessa figura, que o saldo de radiação variou entre $162,64 \mathrm{~W} / \mathrm{m}^{2}$ a $67,54 \mathrm{~W} / \mathrm{m}^{2}$ (janeiro - junho, período chuvoso) e 171,08 W/m² a 137,02 W/ $\mathrm{m}^{2}$ (julho - dezembro, período menos chuvoso). E sua partição sob a forma de calor sensível obteve um pico em novembro (mês da estação menos chuvosa) de $48,64 \mathrm{~W} / \mathrm{m}^{2}$, onde se tem mais entrada de radiação devido a pouca nebulosidade, em contra partida esse fluxo obteve seu menor valor em abril (mês da estação mais chuvosa) de $28,75 \mathrm{~W} / \mathrm{m}^{2}$. Para o fluxo de calor latente foi detectado um máximo em maio (período chuvoso)

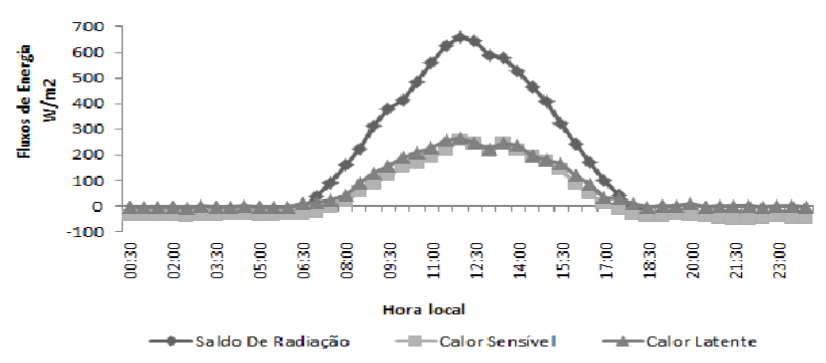

Figura 10 - Variação média horária do saldo de radiação, fluxo de calor sensível (H) e fluxo de calor latente (LE) em Julho de 2003.

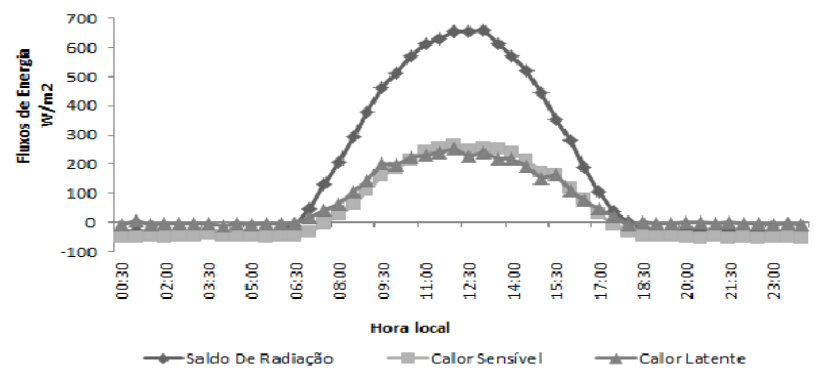

Figura 11 - Variação média horária do saldo de radiação, fluxo de calor sensível (H) e fluxo de calor latente (LE) em Agosto de 2003. com $81,49 \mathrm{~W} / \mathrm{m}^{2}$ e seu mínimo foi observado em janeiro, também época de menos precipitações com $61,73 \mathrm{~W} / \mathrm{m}^{2}$.

Através da Figura 12 pode-se perceber que o saldo de radiação seguiu o padrão esperado de apresentar maiores valores na época menos chuvosa, e consecutivamente, os menores valores na estação mais chuvosa, onde ocorre a interferência do acréscimo na nebulosidade.

No período estudado o fluxo de calor latente superou o fluxo de calor sensível, pois o terreno experimental é alagado constantemente pelo regime de marés, esses valores tendem a ser menor no período em que ocorre diminuição da precipitação.

\subsection{Variação sazonal dos componentes do balanço de energia e Razão de Bowen}

A partição de energia expressa pela Razão de Bowen e a fração do saldo de radiação na forma de calor sensível e calor latente para todo período de estudo, estão apresentadas na Figura 13.

A Razão de Bowen apresentou um valor médio de 0,43 . O maior valor de Bowen para o manguezal ocorreu no mês de agosto com 0,62 , devido à redução no valor médio de calor latente (LE), acompanhado de um acréscimo no valor médio de calor sensível (H). Percebe-se um pico na partição de energia em forma de calor latente em abril de 0,91 e seu mínimo em janeiro de 0,31 ; a menor diferença observada na fração evaporativa do manguezal, definido como a razão entre o fluxo de calor latente e o saldo de radiação (LE/Rn), pode estar relacionada com características fisiológicas da vegetação de manguezal, que pode ter um mecanismo de

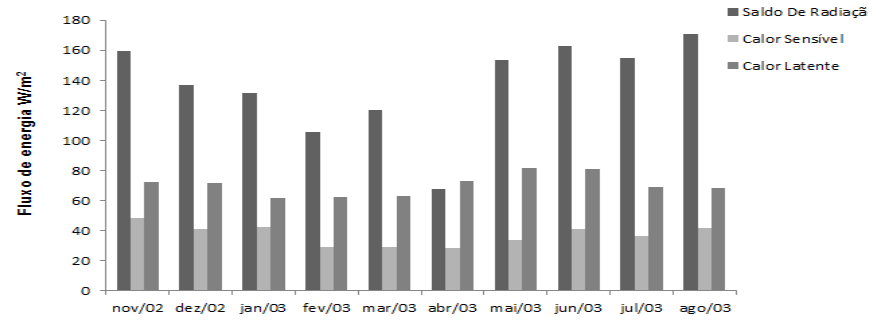

Figura 12 - Variação sazonal dos valores mensais dos componentes do balanço de energia.

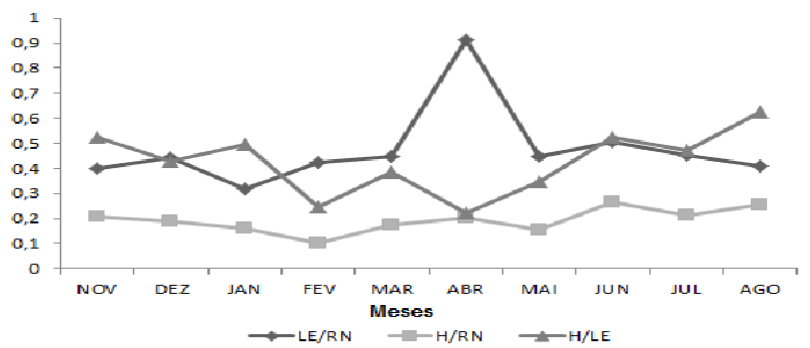

Figura 13 - Variação sazonal da partição dos componentes do Balanço de Energia. 
trocas gasosas menos eficiente do que a vegetação de floresta. (Myers, 1983) concluiu que certas adaptações morfológicas da vegetação desenvolvida em ambiente salino, repercutem em folhas grossas de parênquima mais desenvolvido, menos teor de clorofila, espaços intracelulares menores, menos estômatos e menos cloroplastos. Já para partição do saldo de radiação em forma de calor sensível obteve seu máximo de 0,26 em junho, de maneira inesperada, pois como se pode acompanhar seus maiores valores tendem a se concentrar na época menos chuvosa, mas ao analisar a precipitação de junho na Figura 1, pode-se ver que esse mês foi o que apresentou menor valor de precipitação se comparado aos de mais meses do período chuvoso.

Bowen possui no geral menores valores na estação chuvosa (janeiro a junho), quando os valores de fluxo de calor latente tendem a ser maior e o inverso se observa na estação menos chuvosa (julho a dezembro), quando o fluxo de calor sensível é maior.

\subsection{Aplicação de modelos mecanísticos para determinação dos componentes do saldo de radiação}

Determinação horária do fluxo de calor sensível (H) através dos métodos de Shuttleworth e Penman-Monteith, em comparação aos dados observados.

Em novembro (Figura 14) se tem que entre às 09:30 horas até às 16:00 horas os valores de Penman-Monteith superestimam os valores observados, já Shuttleworth neste mesmo intervalo subestima o real, nos de mais horários os valores de ambos os modelos se aproximam dos valores reais. Em dezembro (Figura 15) se percebe um comportamento semelhante ao do mês de novembro, com uma menor amplitude na diferença entre os modelos e o observado. Para o mês de janeiro (Figura 16), ainda se conserva o padrão bem semelhante ao do mês de dezembro.

Em fevereiro (Figura 17) a relação entre o observado e os modelos se encontra bem próxima com alguns poucos momentos em que ambos os modelos subestimaram os dados coletados. Março (Figura 18) se destacou por apresentar uma configuração diferente dos demais meses, com os modelos superestimando no período da noite e madrugada, já entre às 09:30 horas e às 13:00 horas o observado é subestimado principalmente por PenmanMonteith em alguns momentos deste intervalo.

O mês de abril (Figura 19) é o que se encontra mais conturbado, talvez por apresentar falhas na coleta de dados, porém mesmo assim pode se observar que ele também acompanha os padrões dos meses anteriores, mais semelhante aos meses de fevereiro e março, quando o observado é subestimado pelos dois métodos. Também no mês de maio (Figura 20) o padrão já acompanhado nos meses anteriores se repete, só que com uma leve diferença entre o observado e os modelos que seguem subestimando.

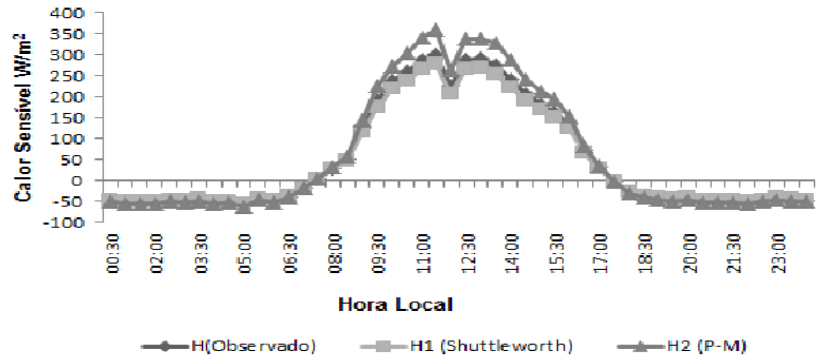

Figura 14 - Comparação entre valores observados e estimados do fluxo de calor sensível (H) para Novembro de 2002.

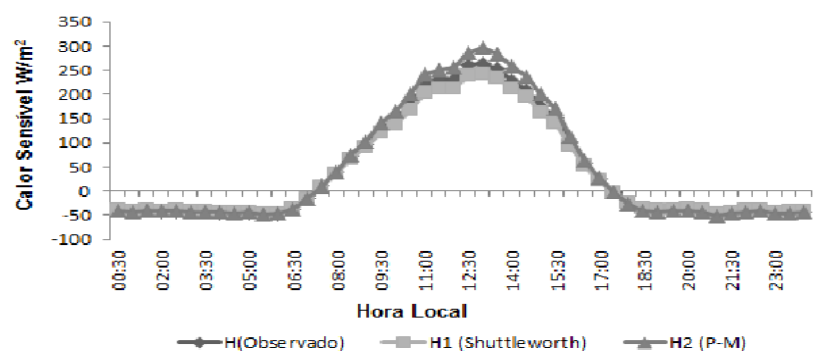

Figura 15 - Comparação entre valores observados e estimados do fluxo de calor sensível (H) para Dezembro de 2002.

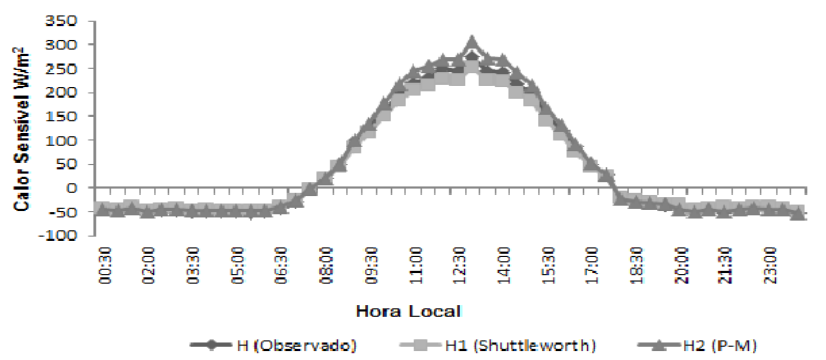

Figura 16 - Comparação entre valores observados e estimados do fluxo de calor sensível (H) para Janeiro de 2003.

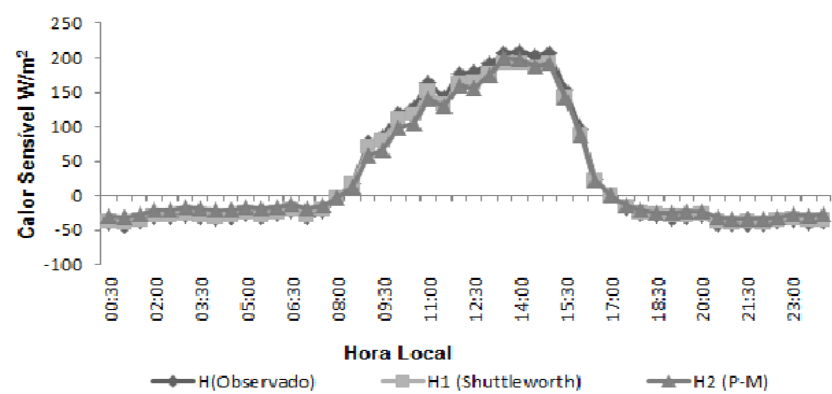

Figura 17 - Comparação entre valores observados e estimados do fluxo de calor sensível (H) para Fevereiro de 2003.

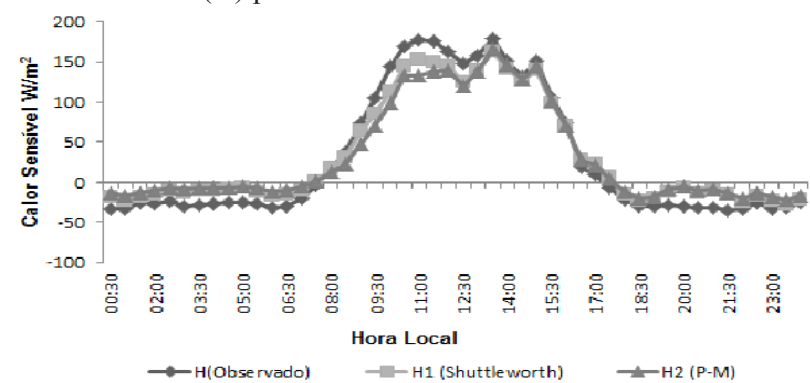

Figura 18 - Comparação entre valores observados e estimados do fluxo de calor sensível (H) para Março de 2003. 
No mês de junho (Figura 21) se percebe que os valores do observado no horário de maior radiação entre as 07:30 horas e 16:00 horas se aproximam aos dois métodos, apenas no período que vai das 12:30 horas até as 14:30 horas o observado fica superestimado por Penman-Monteith e subestimado por Shuttleworrth. Em julho (Figura 22) o método de PenmanMonteith se compara praticamente em todos os horários ao observado, já o método de Shuttleworrth entre 11:30 horas e 15:00 horas subestima pouco o observado. Agosto (Figura 23), entre as 09:00 horas e as 15:30 horas, Penman-Monteith superestima o observado e Shuttleworth segue subestimando pouco o valor real.

Em uma análise geral, o fluxo de calor sensível no período de maior energia disponível, tanto na estação chuvosa, quanto na menos chuvosa os modelos se aproximam dos valores reais com Shuttleworth se mostrando mais eficiente do quePenman-Monteith.

Para o período de menor energia, ou seja, noite e madrugada os modelos se mostram bastante eficientes se equiparando ao observado praticamente em todos os meses, com exceção para o mês de março (Figura 18).

Determinação horária do fluxo de calor latente (LE) através dos métodos de Shuttleworth e PEnman-Monteith, em comparação aos dados observados.

Em novembro (Figura 24), no período entre às 06:00 horas e às 17:00 horas, tanto o observado, quanto os estimados aumentam, porém os valores de Shuttleworth para o mesmo período superestimam os valores reais, enquanto que os valores de Penman-Monteith ficam mais próximos do observado com superestimação em alguns momentos e durante noite e madrugada os dois modelos se equivalem entre si, mas superestimam o valor medido. Em dezembro (Figura 25) o comportamento se assemelha ao de novembro, a diferença esta no fato de que Penman-Monteith em nenhum momento subestima o valor real, e que durante noite e madrugada os modelos se aproximam mais do real. Para janeiro (Figura 26) o padrão é semelhante ao mês de dezembro.

De fevereiro (Figura 27) a maio (Figura 30) os padrões possuem certa semelhança, pois entre 06:30 horas até as 18:30 horas Penman-Monteith sempre se encontra abaixo dos valores reais, enquanto que Shuttleworth começa a intercalar momentos em que se assemelha ao observado e já no final da tarde superestima o real, durante noite e madrugada, tanto o observado, quanto os modelos se equivalem com valores bem próximos de zero.

Em junho (Figura 31), julho (Figura 32) e agosto (Figura 33), os padrões são parecidos com Shuttleworth novamente se distanciando e superestimando o valor real, e Penman-Monteith se mantendo sempre mais próximo do observado com alguns momentos em que ele aparece abaixo ou semelhante ao real, durante noite e madrugada Shuttleworth e Penman-Monteith se assemelham, mas superestimam um pouco o observado.

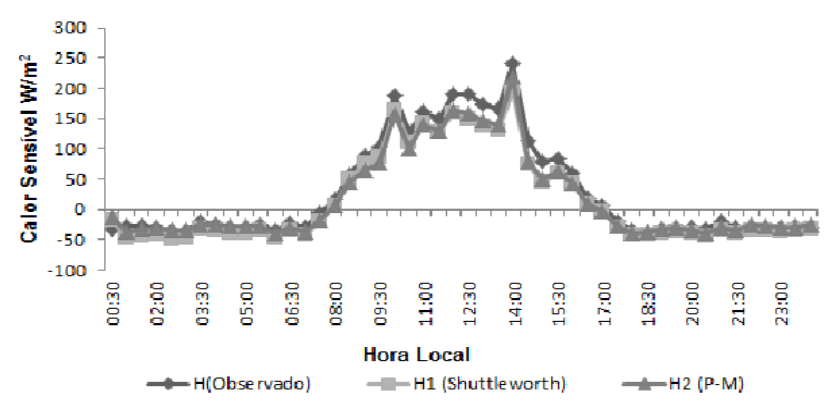

Figura 19 - Comparação entre valores observados e estimados do fluxo de calor sensível (H) para Abril de 2003.

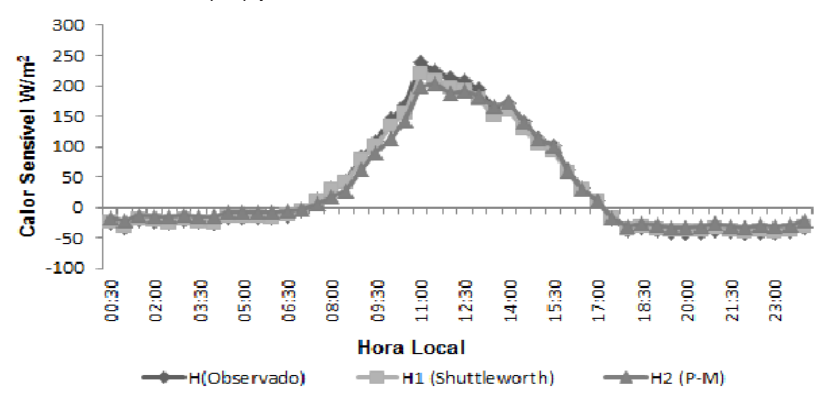

Figura 20 - Comparação entre valores observados e estimados do fluxo de calor sensível (H) para Maio de 2003.

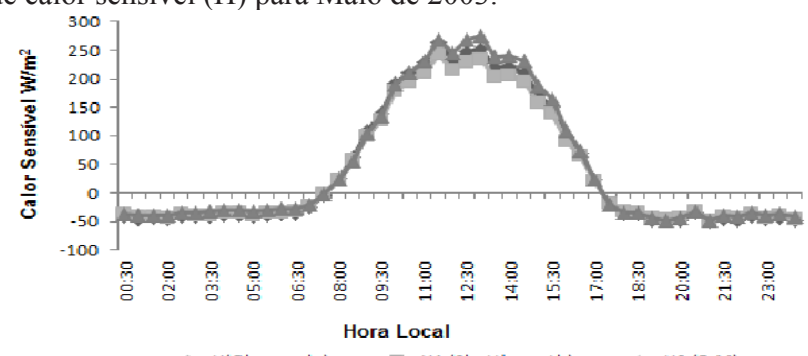

Figura 21 - Comparação entre valores observados e estimados do fluxo de calor sensível (H) para Junho de 2003.

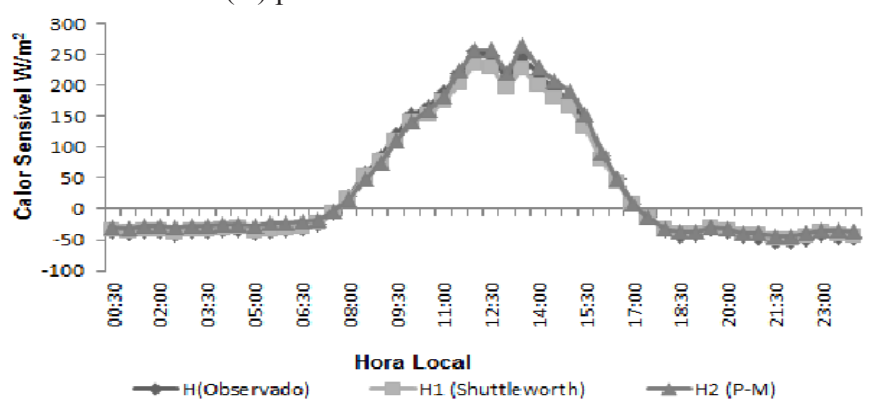

Figura 22 - Comparação entre valores observados e estimados do fluxo de calor sensível (H) para Julho de 2003.

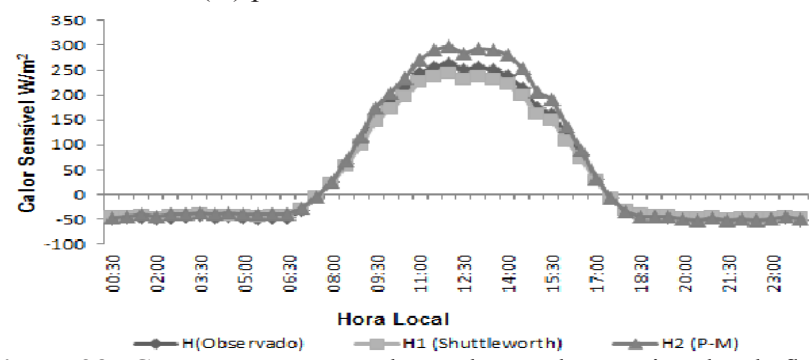

Figura 23 - Comparação entre valores observados e estimados do fluxo de calor sensível (H) para Agosto de 2003. 


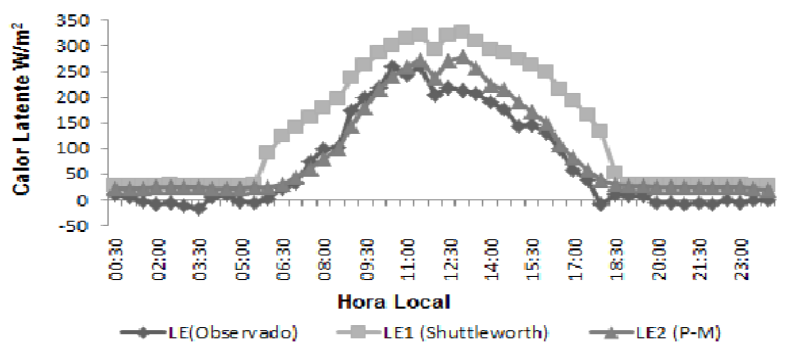

Figura 24 - Comparação entre valores observados e estimados do fluxo de calor latente (LE) para Novembro de 2002.

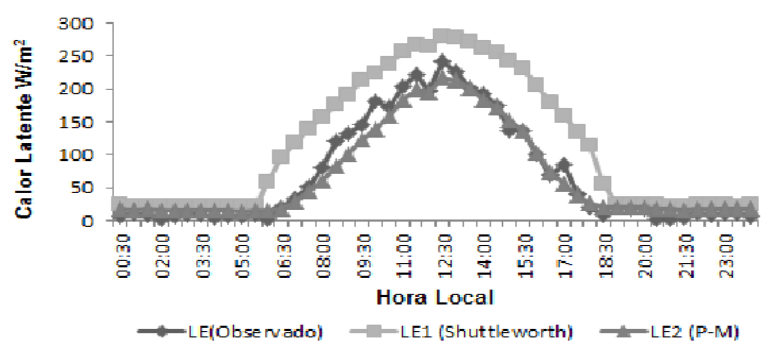

Figura 25 - Comparação entre valores observados e estimados do fluxo de calor latente (LE) para dezembro de 2002.

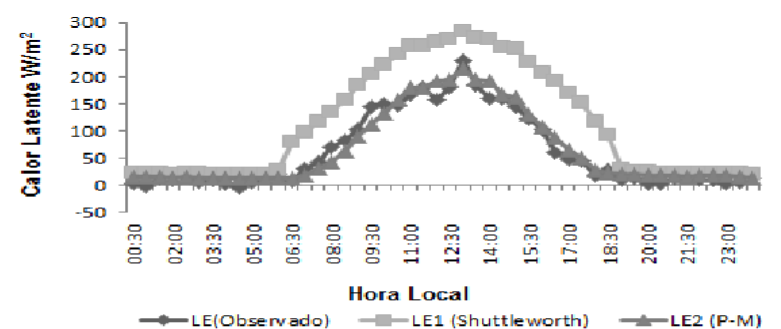

Figura 26 - Comparaçao entre valores observados e estımados do Huxo de calor latente (LE) para Janeiro de 2003.

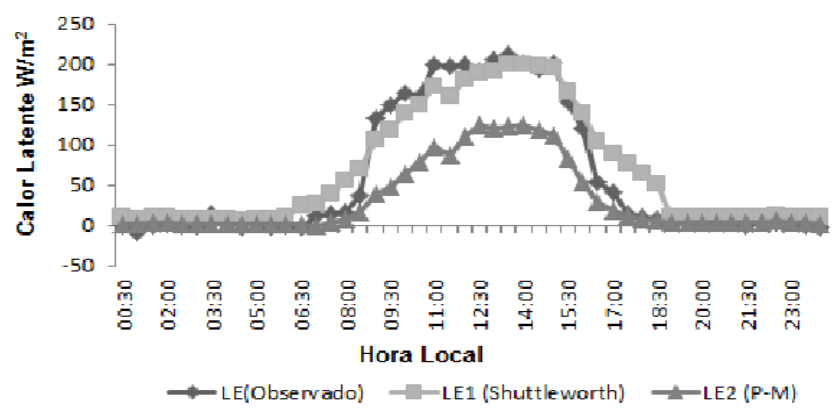

Figura 27 - Comparação entre valores observados e estimados do fluxo de calor latente (LE) para Fevereiro de 2003.

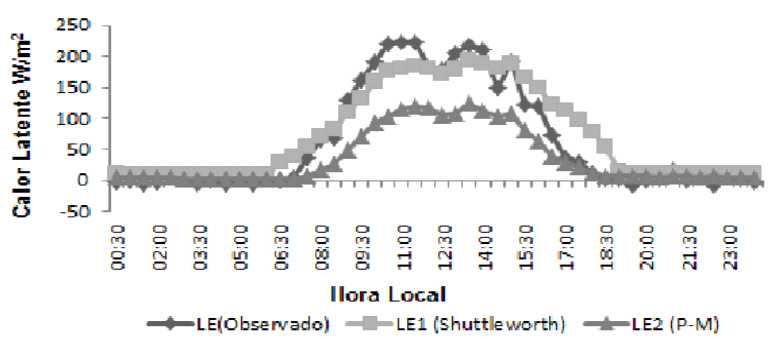

Figura 28 - Comparação entre valores observados e estimados do fluxo de calor latente (LE) para Março de 2003.

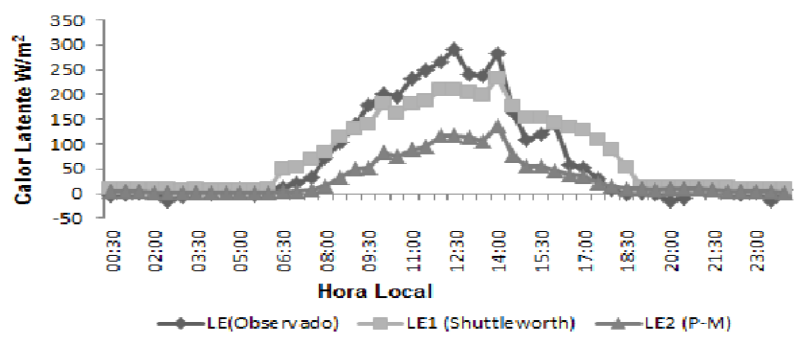

Figura 29 - Comparação entre valores observados e estimados do fluxo de calor latente (LE) para Abril de 2003.

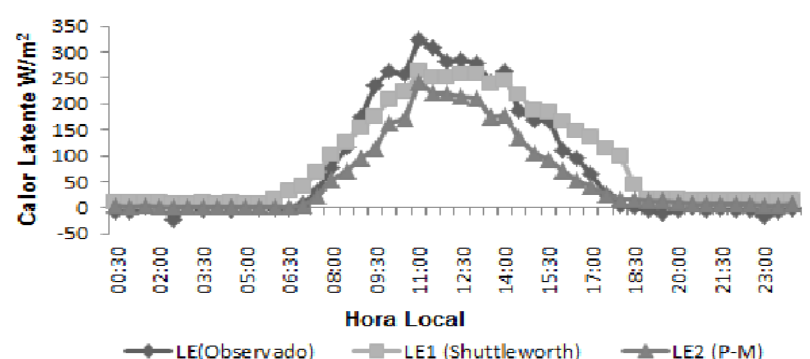

Figura 30 - Comparação entre valores observados e estimados do fluxo de calor latente (LE) para Maio de 2003.

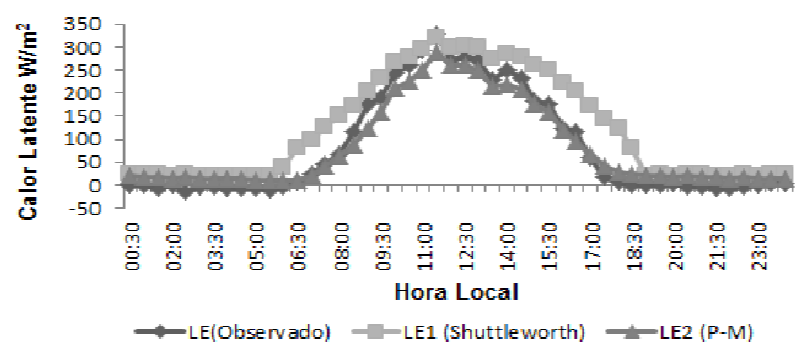

Figura 31 - Comparação entre valores observados e estimados do fluxo de calor latente (LE) para Junho de 2003.

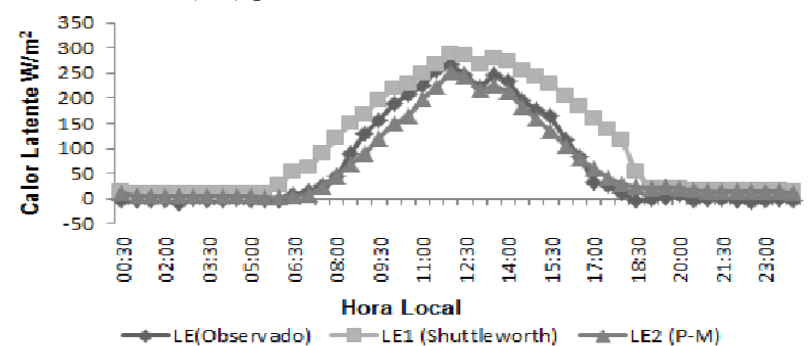

Figura 32 - Comparação entre valores observados e estimados do fluxo de calor latente (LE) para Julho de 2003.

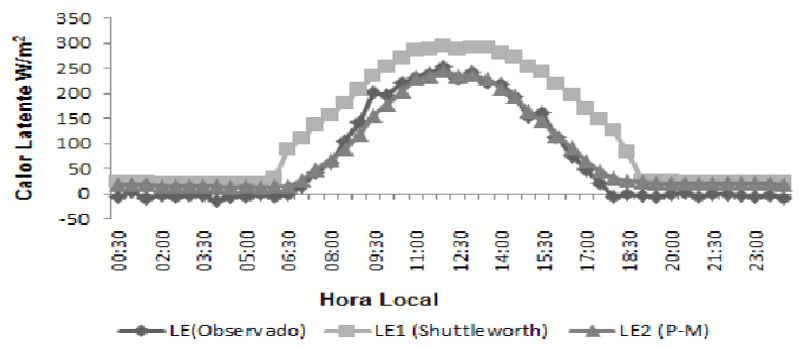

Figura 33 - Comparação entre valores observados e estimados do fluxo de calor latente (LE) para Agosto de 2003. 
No geral para o fluxo de calor latente se observa que os modelos apresentaram uma maior diferença em relação ao observado, quando se compara ao ocorrido para o calor sensível. $\mathrm{Na}$ estação menos chuvosa, para o período de maior energia disponível, entre 07:00 horas e às 17:00 horas, Shuttleworth superestimou bastante o observado, com Penman-Monteith se mostrando mais próximo dos valores reais. $\mathrm{Na}$ estação chuvosa, ambos os modelos tendem a subestimar o observado com Shuttleworth se mostrando mais eficientes nestes horários.

Durante noite e madrugada os métodos se comportam com valores bem próximos do real, com uma leve tendência de superestimação durante alguns meses da estação menos chuvosa.

A estimativa para o fluxo de calor latente se torna mais complexa uma vez que os modelos envolvem além da resistência aerodinâmica a resistência estomática, sendo esta de difícil definição uma vez que envolve a parte fisiológica da planta.

\section{CONCLUSÕES}

O saldo de radiação se comportou de maneira diferenciada nas duas estações marcantes da região, apresentando seus maiores valores na época menos chuvosa (julho-dezembro) que variaram entre $600 \mathrm{~W} / \mathrm{m}^{2}$ a $700 \mathrm{~W} / \mathrm{m}^{2}$. Os componentes do balanço de energia apresentaram variação sazonal bem caracterizada, com o fluxo de calor sensível apresentando valores maiores do que o fluxo de calor latente entre os horários da manhã e fim de tarde na estação menos chuvosa. Contudo, nos meses de julho e agosto o saldo de radiação foi bem dividido no manguezal entre os dois fluxos, pois calor sensível e calor latente apresentavam valores bem próximos.

A variação média dos fluxos mostrou que o calor latente obteve os maiores valores em quase todo o período estudado, o que demonstra que para este ecossistema que vive sobre o regime de fluxo e refluxo de marés, portanto frequentemente inundado, a maior parte do saldo de radiação foi utilizada para evaporação da água.

A razão de Bowen média mensal para o período estudado apresentou no geral valores baixos, reafirmando que a maior parcela de energia foi utilizada na forma de calor latente.

As estimativas de fluxos de energia no manguezal utilizando os modelos mecanísticos propostos por Shuttleworth e Penman-Monteith mostraram resultados satisfatórios, principalmente na estimativa do fluxo de calor sensível, onde às simulações apresentaram valores muito próximos dos valores medidos, principalmente nos resultados apresentados pelo modelo Shuttleworth. Quanto ao fluxo de calor latente, os modelos tiveram momentos de alternância com relação a sua eficiência, pois no horário que se estende das 07:00 horas às 17:00 horas, para a estação menos chuvosa Penman-Monteith, se mostrou mais hábil, já para a estação chuvosa Shuttleworth se mostrou mais eficiente nos mesmos horários.

Para os horários da noite e madrugada para ambos os fluxos os modelos se mostraram eficientes, sempre se mantendo próximos dos valores reais.

\section{AGRADECIMENTOS}

Ao projeto LBA pelo fornecimento dos dados, ao projeto RPCH pelo espaço físico cedido para a elaboração e todos que colaboraram para realização deste trabalho.

\section{REFERÊNCIAS BIBLIOGRÁFICAS}

BRUTSAERT, W. H. Evaporation into the atmosphere. Dordrecht: D. Reidel., 1982.

DICKINSON, R. E. Modeling evapotranspiration for three-dimensional global climate models. In: HANSEN, J. E.; TAKAHASHI, T. (Eds.). Climate processes and climate sensitivity. Washington: American Geophysical Union, v.4, p.58-72, 1984.

INSTITUTO NACIONAL DE METEOROLOGIA(INMET). Normais climatológicas. Brasília, DF, 1992, 155 p.

MALHI, Y. et al. Carbon dioxide transfer over a central Amazonian rain forest. Journal of Geophysical Research, v.103, p.3159331612. 1998.

MONCRIEFF, J.B. et al. System to measure surface fluxes of momentum, sensible heat, water vapour and carbon dioxide. Journal of hidrology, v.188-189, p. 589-611. 1997.

MONTEITH, J. L. Evaporation and environment. Symposia of the Society for Experimental Biology, v.19, p.205-234. 1965.

MIELKE, M. S. et al. Stomata controlo f transpiration in the canopy a clonal Eucaliptus grandis plantion. Trees, v.13, p.152-160. 1999.

MYERS, V. I. Remote sensing application in agriculture. In: COLWELL, R. N., (Ed.). Manual of remote sensing falls church American Society of Photogrammetry, p. 2111-2228. 1983.

NEVES, L. O et al. Balanço de energia em uma cultura de feijão caupi (Vigna unguiculata L.) no estado do Pará. Revista Brasileira de Agrometeorologia, v.16, p. 21-30. 2008.

NICHOLS, W. D. Energy budgets and resistances to energy transport in sparsely vegetated rangeland. Agricultural and Forest Meteorology, v.60, n.3-4, p.147-221. 1992.

PEREIRA, A. R.; VILlA NOVA, N. A., SEDIYAMA, G. C. Evapo(transpi)ração. Piracicaba: FEALQ, 1997. 183p.

SANTOS ALVALÁ, R. C. Estudo da partição de energia em terrenos complexos (áreas desflorestadas e florestas). 1993. 149p. Tese (Doutorado em Meteorologia)-Instituto Nacional de Pesquisas Espaciais, São José dos Campos, 1993.

SHUTTLEWORTH, W.J. Corrections for the effects of background concentrations change and sensor drift in real-time eddy correlations systems. Boundary Layer Meteorology, v.42, p.167-180. 1988. 